\title{
Mechanical Performance of Honeycomb Sandwich Structures Using Three-Point Bend Test
}

\author{
Tayyab Subhani \\ Department of Mechanical Engineering, \\ College of Engineering, University of Hail \\ Hail, Saudi Arabia \\ ta.subhani@uoh.edu.sa
}

\begin{abstract}
In this study, honeycomb sandwich structures were prepared and tested. Facesheets of sandwich structures were manufactured by carbon fiber epoxy matrix composites while Nomex ${ }^{\circledR}$ honeycomb was used as core material. An epoxy-based adhesive film was used to bond the composite facesheets with honeycomb core. Four different curing temperatures ranging from $100^{\circ} \mathrm{C}$ to $130^{\circ} \mathrm{C}$ were applied with curing times of $2 \mathrm{~h}$ and $3 \mathrm{~h}$. Three-point bend test was performed to investigate the mechanical performance of honeycomb sandwich structures and thus optimize the curing parameters. It was revealed that the combination of a temperature of $110^{\circ} \mathrm{C}$ along with a curing time of $2 \mathrm{~h}$ offered the optimum mechanical performance together with low damage in honeycomb core and facesheets.
\end{abstract}

Keywords-honeycomb sandwich; mechanical; three-point bend test; epoxy; carbon fiber

\section{INTRODUCTION}

Honeycomb sandwich structures are widely used for aerospace structural applications. A honeycomb sandwich structure comprises of two stiff and strong skins or facesheets joined together with a honeycomb core. Such a structural configuration offers light weight with high stiffness. Good fatigue strength and thermal insulation are additional attributes of honeycomb sandwich structures [1]. In sandwich structures, facesheets carry the bending stress applied to the structure while the honeycomb core bears the shear loads and increases the stiffness of the sandwich structure while holding the two facesheets. Moreover, increase in the thickness of honeycomb core increases stiffness and flexural strength of sandwich structures. In addition to honeycomb, foam and wood are also used as core materials in sandwich structures. However, due to its stiffness, crushing strength and fatigue properties, the honeycomb core enjoys a special edge over other core structures [2]. Honeycomb cores are made of polymeric, metallic and ceramic materials such as aluminum, carbon, fiberglass, alumina and kevlar. Facesheets are made of steels, aluminum and composite materials.

For the bonding of facesheets with the honeycomb core, adhesives, fasteners and adhesive films are used. The properties of adhesive materials play a vital role in the overall mechanical performance of honeycomb structures [3]. The adhesive material firmly attaches the facesheets to the honeycomb core in order to effectively transfer the load from one facesheet to another through the core [4]. Therefore, good bonding between the facesheets and the honeycomb core defines the load-bearing capacity of a sandwich structure. Upon the application of a bending load, shear stresses are developed at the interface, which is actually the adhesive joint between the core and the facesheet. The shear stress may debond the two components of the sandwich structure thus paving the way to a structural disaster. Therefore, the adhesive joint formed at the interface by an adhesive material influences significantly the mechanical performance of a honeycomb sandwich structure [3].

Evaluation of mechanical properties is the prime requisite before taking a sandwich structure into actual implementation [3]. Three-point bend test is usually carried out to investigate the shear and flexural rigidities of sandwich structures. In particular, properties such as facing bending strength, core shear strength, core shear modulus and transverse shear rigidity can be obtained using the three-point bend test. In [4], numerical investigation of the three-point bend test was performed on sandwich honeycomb structures containing aluminum facesheets. Numerical and experimental study on the bending behavior of honeycomb sandwich panel with ceramic facesheet is shown in $[5,6]$. Air-blast loading of sandwich structures is another way of mechanical characterization [7]. In addition to the mechanical performance evaluation, the failure mechanism of sandwich structures is also critical to assess the way in which the damage will result [8]. The absorption of crushing energy of sandwich structures has been evaluated during damage in [9]. The understanding of interfacial fracture in sandwich structures is yet another prime requirement [10]. As a result, a variety of tests have been devised to investigate the core-facesheet adhesion $[1,2]$.

In the current study, honeycomb structures were tested under three-point bend test to explore their mechanical properties after bonding the facesheets and the honeycomb core with an epoxy-based adhesive. Facesheets were made of carbon fiber epoxy matrix composite while Nomex ${ }^{\circledR}$ honeycomb was used as core. Compression bonding method was used to cure the adhesive film using 4 different temperatures and 2 curing times. Based upon the acquired data, the curing parameters of the adhesive films were optimized. 


\section{EXPERIMENT DESCRIPTION}

The honeycomb sandwich structures were prepared by employing carbon fiber epoxy matrix composite facesheets of $1 \mathrm{~mm}$ thickness, Nomex ${ }^{\circledR}$ honeycomb core of $20 \mathrm{~mm}$ thickness and $5.5 \mathrm{~mm}$ cell size, and epoxy-based adhesive film. The adhesive film was procured from CNME International, China with the trade name of CNMEHP-272D and $0.34-0.38 \mathrm{~mm}$ thickness. The hexagonal phenolic impregnated Nomex ${ }^{\circledR}$ honeycomb core was purchased from Armicore Composite Company, China. The composite facesheets were prepared indigenously, for details see [11]. For the manufacturing of sandwich structures, the adhesive film was applied on the rough surface of the two composite facesheets and was bonded with the honeycomb core. The sandwich panel was gripped between the metallic plates and loaded under compression. In total, 8 sandwich panels were prepared for curing at 4 different temperatures of $100^{\circ} \mathrm{C}, 110^{\circ} \mathrm{C}, 120^{\circ} \mathrm{C}$ and $130^{\circ} \mathrm{C}$ and 2 curing times of $2 \mathrm{~h}$ and $3 \mathrm{~h}$. The specimens cut from the 8 sandwich panels were tested under three-point bend test according to ASTM standard C393/C393M. Rectangular shaped specimens with $203.2 \mathrm{~mm}$ length, $76.2 \mathrm{~mm}$ width and $\sim 22 \mathrm{~mm}$ thickness were used. Four mechanical properties, namely (a) core ultimate shear stress, (b) facing bending stress, (c) core shear rigidity, and (d) core shear modulus were evaluated by the three-point bend test in order to evaluate the mechanical performance of honeycomb sandwich structures.

\section{RESULTS AND DISCUSSION}

The load-displacement curves are shown in Figures 1 and 3, respectively. The values of the mechanical properties including facing bending strength, core shear strength, core shear modulus and transverse shear rigidity are shown in Figures 2 and 4.

\section{A. Two Hour Curing Time}

Figure 1 displays the load-displacement curves of the honeycomb structures cured from $100^{\circ} \mathrm{C}$ to $130^{\circ} \mathrm{C}$ for $2 \mathrm{~h}$ under three-point bending load. Increase in peak load values was observed when the curing temperature increased from $100^{\circ} \mathrm{C}$ to $110^{\circ} \mathrm{C}$. This increase in peak load value resulted in enhancing the facing bending strength from $48.6 \pm 2.4 \mathrm{MPa}$ to $57.2 \pm 3.1 \mathrm{MPa}$, core shear strength from $0.62 \pm 0.03 \mathrm{MPa}$ to $0.73 \pm 0.05 \mathrm{MPa}$, core shear modulus from $37.0 \pm 5.3 \mathrm{MPa}$ to $39.1 \pm 4.1 \mathrm{MPa}$ and transvers shear rigidity from $60.1 \pm 3.5 \mathrm{KN}$ to $63.1 \pm 2.4 \mathrm{KN}$ respectively, as shown in Figure 2. However, further increase in temperature, to $120^{\circ} \mathrm{C}$ and $130^{\circ} \mathrm{C}$, lowered peak load values, $1.89 \mathrm{KN}$ and $1.80 \mathrm{KN}$ respectively, while simultaneously it lowered the mechanical properties: facing bending strength from $46.2 \pm 1.8 \mathrm{MPa}$ to $43.9 \pm 0.8 \mathrm{MPa}$, core shear strength from $0.59 \pm 0.01 \mathrm{MPa}$ to $0.56 \pm 0.02 \mathrm{MPa}$, core shear modulus from $23.3 \pm 2.1 \mathrm{MPa}$ to $19.4 \pm 2.7 \mathrm{MPa}$ and transverse shear rigidity from $38.5 \pm 1.4 \mathrm{KN}$ to $32.9 \pm 1.7 \mathrm{KN}$ respectively. The decrease in mechanical properties may be caused by the distortion in the fillet leading to unsymmetrical shape and porosity created because of the evaporation of volatile contents in the adhesive film $[12,13]$.

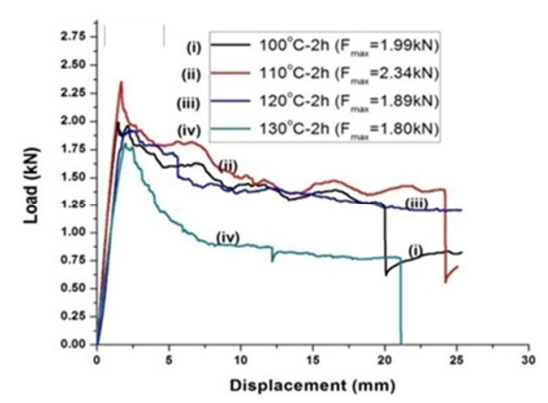

Fig. 1. Load-displacement curves of honeycomb sandwich structures cured at $100^{\circ} \mathrm{C}, 110^{\circ} \mathrm{C}, 120^{\circ} \mathrm{C}$ and $130^{\circ} \mathrm{C}$ for $2 \mathrm{~h}$.
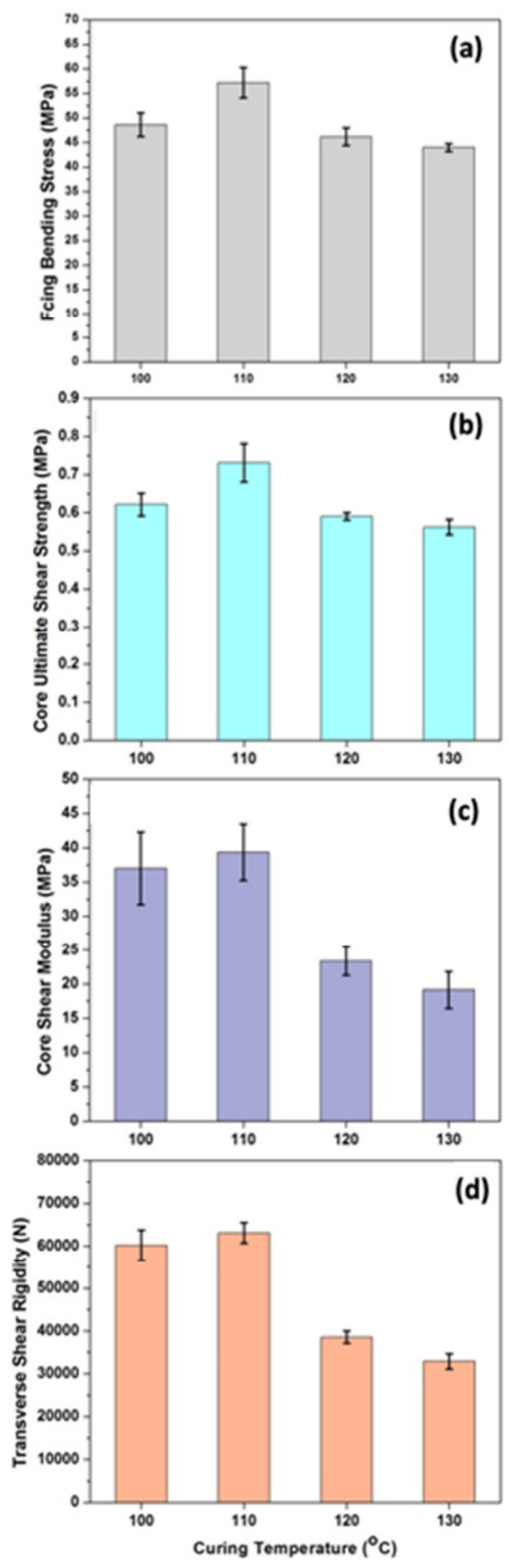

Fig. 2. (a) Facing bending strength, (b) core shear strength, (c) core shear modulus, and (d) transverse shear rigidity of honeycomb sandwich structures cured at $100^{\circ} \mathrm{C}, 110^{\circ} \mathrm{C}, 120^{\circ} \mathrm{C}$ and $130^{\circ} \mathrm{C}$ for $2 \mathrm{~h}$. 


\section{B. Three Hour Curing Time}

Three-point bend test results of honeycomb sandwich structures cured at $100^{\circ} \mathrm{C}, 110^{\circ} \mathrm{C}, 120^{\circ} \mathrm{C}$ and $130^{\circ} \mathrm{C}$ for $3 \mathrm{~h}$, shown in Figures 3 and 4 followed the same trend with the honeycomb sandwich structures cured for $2 \mathrm{~h}$. Peak load values were observed at $100^{\circ} \mathrm{C}$ and $110^{\circ} \mathrm{C}$, respectively, thus producing facing bending strength of $48.8 \pm 2.3 \mathrm{MPa}$ and $54.7 \pm 3.5 \mathrm{MPa}$, cores shear strength of $0.62 \pm 0.03 \mathrm{MPa}$ and $0.69 \pm 0.07 \mathrm{MPa}$, core shear modulus of $33.2 \pm 4.3 \mathrm{MPa}$ and $38.1 \pm 5.6 \mathrm{MPa}$ and transverse shear rigidity of $56.2 \pm 2.6 \mathrm{KN}$ and $64.0 \pm 4.2 \mathrm{KN}$ respectively. Further increase in curing temperature to $120^{\circ} \mathrm{C}$ and $130^{\circ} \mathrm{C}$ reduced peak load values and thus the mechanical properties of composite honeycomb sandwich panels. Facing bending strength reduced from $51.0 \pm 2.6 \mathrm{MPa}$ to $33.2 \pm 1.1 \mathrm{MPa}$, core shear strength from $0.65 \pm 0.04 \mathrm{MPa}$ to $0.42 \pm 0.01 \mathrm{MPa}$, core shear modulus from $29.4 \pm 2.7 \mathrm{MPa}$ to $17.3 \pm 0.8 \mathrm{MPa}$ and transverse shear rigidity from $49.4 \pm 2.0 \mathrm{KN}$ to $29.8 \pm 1.1 \mathrm{KN}$ respectively, as shown in Figure 4.

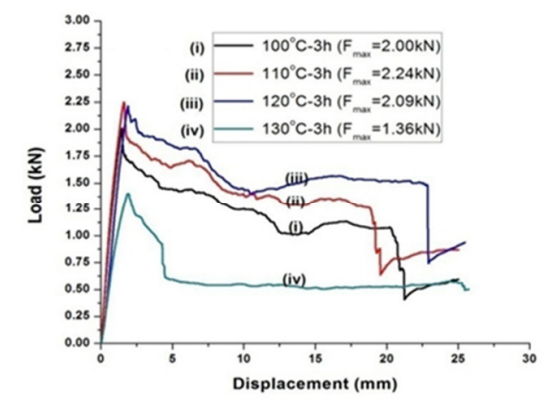

Fig. 3. Load-displacement curves of honeycomb sandwich structures cured at $100^{\circ} \mathrm{C}, 110^{\circ} \mathrm{C}, 120^{\circ} \mathrm{C}$ and $130^{\circ} \mathrm{C}$ for $3 \mathrm{~h}$.

\section{Cross-Sectional Photographs}

The cross-sectional views of sandwich structures, which showed maximum and minimum mechanical properties after three-point bend test, are shown in Figures 5 and 6 . The sandwich structure cured at $130^{\circ} \mathrm{C}$ for $3 \mathrm{~h}$ (Figure 5(b)) showed minimum mechanical properties, which may be caused by to the presence of unsymmetrical fillets or poor interfacial adhesion [11]. The cross-sectional magnified view of this specimen after the three-point bend test is shown in Figure 6(b), which shows local indentation as well as shear deformation failure of the honeycomb core spread over a vast area. In contrast, the sandwich structure processed at $110^{\circ} \mathrm{C}$ for $2 \mathrm{~h}$ offered maximum mechanical properties (Figure 5(a)), with the magnified view of this specimen (Figure 6(a)) indicating a localized damage zone. These two sandwich structures were intentionally selected because one of these showed maximum values while the other displayed minimum values. The crosssectional photographs are presented to reveal the effect of variations of curing parameters of adhesive films upon the failure modes of honeycomb cores. The upper facesheet failures are clearly visible in the middle of the sandwich structures, which are due to the loading span. The upper facesheets in the sandwich structures were under compressive load. Upon reaching the peak load, the load drops continuously along with the crushing of the honeycomb core (Figures 1 and 3 ). The process continues until the failure of the upper facesheet. The load decreases due to the fact that the load exceeds the compression strength of the structures, which is a combination of honeycomb core strength, adhesive film strength and the stiffness of the facesheets [12].
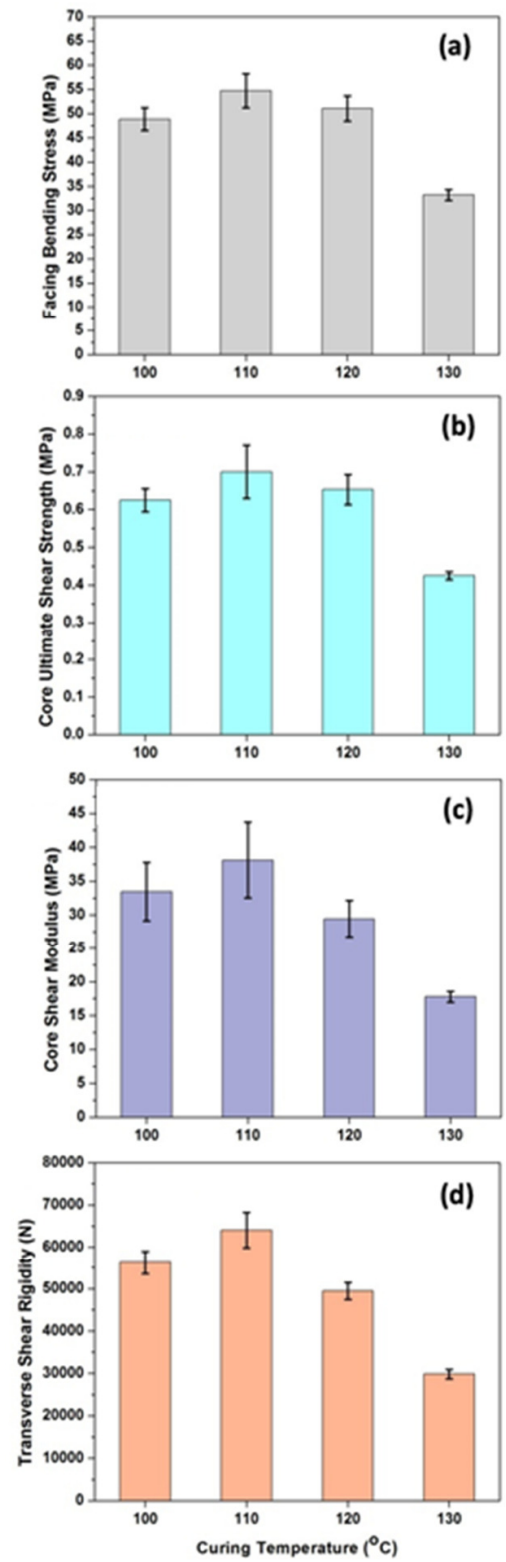

Fig. 4. (a) Facing bending strength, (b) core shear strength, (c) core shear modulus, and (d) transverse shear rigidity of honeycomb sandwich structures cured at $100^{\circ} \mathrm{C}, 110^{\circ} \mathrm{C}, 120^{\circ} \mathrm{C}$ and $130^{\circ} \mathrm{C}$ for $3 \mathrm{~h}$.

The local indentations on the upper facesheets are also clearly visible, which may be due to localized core compression (Figure 5). As discussed above, the magnified images of the same specimens (Figure 6) show that the structure with maximum mechanical properties exhibited a localized damage in the honeycomb core while the structure 
with minimum mechanical properties exhibited damage in honeycomb core at a large scale. This indicates that the good quality bonding of the facesheet with honeycomb core promotes the mechanical properties despite the fact that the compressive strength of honeycomb core shows the same value.

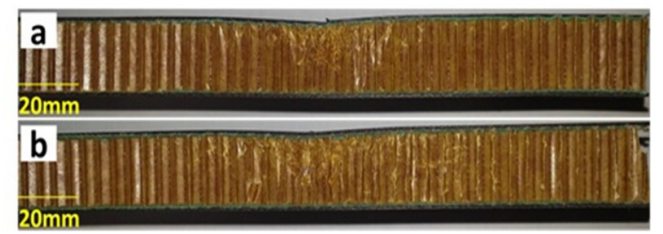

Fig. 5. Cross-sectional views of sandwich structures cured at (a) $110^{\circ} \mathrm{C}$ for $2 \mathrm{~h}$ and (b) $130^{\circ} \mathrm{C}$ for $3 \mathrm{~h}$.

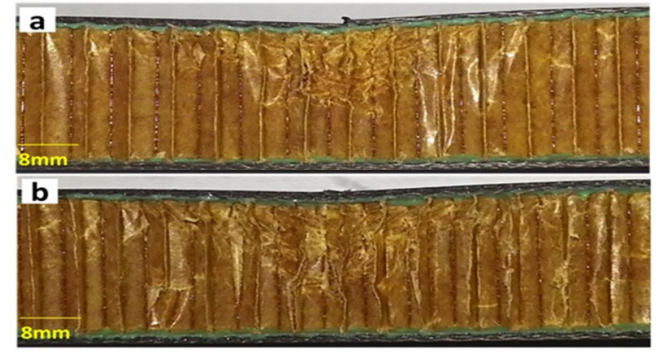

Fig. 6. Cross-sectional magnified views of sandwich structures cured at (a) $110^{\circ} \mathrm{C}$ for $2 \mathrm{~h}$ and (b) $130^{\circ} \mathrm{C}$ for $3 \mathrm{~h}$.

\section{Effect of Curing Temperature and Time}

Experimental data and photographic observations indicate that both curing temperature and curing time of adhesive film affect the mechanical performance of honeycomb sandwich structures. Optimized curing parameters for composite honeycomb structures were found to be $110^{\circ} \mathrm{C}$ for $2 \mathrm{~h}$, at which the sandwich panels showed maximum mechanical properties which may be caused by the formation of symmetrical fillets [13]. At the specified curing parameters, the honeycomb structures showed maximum peak loads prior to the deformation of the core and failure of upper facesheet. The related mechanical properties of the sandwich structures at these parameters were also higher than the other structures'. At optimized curing parameters, the adhesive film forms a suitable fillet between the honeycomb core and the facesheets, which in turn transfers the load effectively from one facesheet to another through the core. It should be noted that increase in temperature helps the flow of adhesive film toward the walls of the core and thus making the film less viscous. However, at the same time the increased temperature promotes the curing of the adhesive film. As a result, the mechanical properties of honeycomb sandwich structures increased by increase in the temperature from $100^{\circ} \mathrm{C}$ to $110^{\circ} \mathrm{C}$ after preparing a symmetrical fillet while further rise in temperature resulted in premature curing of the film without the formation of a uniform fillet.

\section{CONCLUSION}

Honeycomb sandwich structures were prepared by using carbon fiber epoxy matrix composite facesheets, Nomex ${ }^{\circledR}$ honeycomb core and epoxy-based adhesive film. Compression technique was utilized to prepare sandwich structures by optimizing the curing parameters of the adhesive film. Temperature of $110^{\circ} \mathrm{C}$ and curing time of $2 \mathrm{~h}$ exhibited optimum mechanical performance, i.e. maximum load bearing capability and associated mechanical properties. The ability of the flow of adhesive film and the formation of adequate adhesive fillets are the possible reasons behind the increased mechanical properties at optimized parameters of adhesive film. Localized damage area in optimized honeycomb structure was also found to be lower than the one observed in structures showing poor mechanical performance.

\section{REFERENCES}

[1] J. Avery, B. V. Sankar, "Compressive failure of sandwich beams with debonded face-sheets", Journal of Composite Materials, Vol. 34, No. 14, pp. 1176-1199, 2000

[2] W. J. Cantwell, P. Davies, "A test technique for assessing core-skin adhesion in composite sandwich structures", Journal of Materials Science Letters, Vol. 13, No. 3, pp. 203-205, 1994

[3] A. Johnson, G. D. Sims, "Mechanical properties and design of sandwich materials", Composites, Vol. 17, No. 4, pp. 321-328, 1986

[4] M. Giglio, A. Gilioli, A. Manes, "Numerical investigation of a three point bending test on sandwich panels with aluminum skins and Nomex тм honeycomb core", Computational Materials Science, Vol. 56, pp. 6978,2012

[5] Z. Wang, Z. Li, W. Xiong "Numerical study on three-point bending behavior of honeycomb sandwich with ceramic tile", Composites Part B: Engineering, Vol. 167, pp. 63-70, 2019

[6] Z. Wang, Z. Li, W. Xiong "Experimental investigation on bending behavior of honeycomb sandwich panel with ceramic tile face-sheet", Composites Part B: Engineering, Vol. 164, pp. 280-286, 2019

[7] G. S. Langdon, C. J. von Klemperer, B. K, Rowland, G. N. Nurick, "The response of sandwich structures with composite face sheets and polymer foam cores to air-blast loading: preliminary experiments", Engineering Structures, Vol. 36, pp. 104-112, 2012

[8] H. Fan, Q. Zhou, W. Yang, Z. Jingjing, “An experimental study on the failure mechanims of woven textile sandwich panels under quasi-static loading", Composites Part B: Engineering, Vol. 41, No. 8, pp. 686-692, 2010

[9] O. Velecela, M. S. Found, C. Soutis, "Crushing energy absorption of GFRP sandwich panels and corresponding monolithic laminates", Composites Part A: Applied Science and Manufcaturing, Vol. 38, No. 4, pp. 1149-1158, 2007

[10] W. J. Cantwell, R. Scudamore, J. Ratcliffe, P. Davies, "Interfacial fracture in sandwich laminates", Composites Science and Technology, Vol. 59, No.14, pp. 2079-2085, 1999

[11] U. Farooq, M. S. Ahmad, S. A. Rakha, N. Ali, A. A. Khurram, T. Subhani, "Interfacial mechanical performance of composite honeycomb sandwich panels for aerospace applications", Arabian Journal for Science and Engineering, Vol. 42, No. 5, pp. 1775-1782, 2017

[12] R. Okada, M. T. Kortschot, "The role of the resin fillet in the delimination of honeycomb sandwich structures", Composites Science and Technology, Vol. 62, No. 14, pp. 1811-1819, 2002

[13] J. Rion, Y. Leterrier, J. A. E. Manson, "Prediction of the adhesive fillet size for skin to honeycomb core bonding in ultra-light sandwich structures", Composites Part A: Applied Science and Manufacturing, Vol. 39, No. 9, pp. 1547-1555, 2008 